\title{
Integrating Experiential Learning and Accreditation Requirements - A Case Study Based Course
}

\author{
Khaled Medini \\ Mines Saint-Etienne, Univ Clermont Auvergne, CNRS, UMR 6158 LIMOS, Institut Henri \\ Fayol, F - 42023, Saint-Etienne France \\ khaled.medini@emse.fr
}

\begin{abstract}
The increasingly evolving industrial context in manufacturing and service industries calls for an adaptation of the practices and content of engineering education curricula. More active learning approaches are required in order to easily grasp new business challenges and strategies, such as customer centric enterprise and mass customisation. This paper reports on a case study based lecture about mass customisation which was given to students pursuing a Master of Science degree in Industrial Engineering. The lecture echoes the Kolb model for Experiential Learning and refers to guidelines about accreditation requirements. An analysis of the achievement of learning outcomes is realized based a student survey conducted upon two different classes.
\end{abstract}

Keywords: Industrial Transition, Case Study, Experiential Learning, Accreditation, Mass Customisation.

\section{Introduction}

Manufacturing and service industries challenges are increasingly evolving which calls for a proactivity of the company so as to keep up with these evolutions. Recent technological advances, increasing market segmentation and individualised demands, competition on both prices and quality, are among the factors motivating companies to pursue more customer centric business strategies, such as mass customisation (MC). In a simple way, MC aims to fulfil customer individual demands with near mass production efficiency (Salvador et al., 2009; Medini, 2015). A full understanding of $\mathrm{MC}$ and customer orientation in operations management requires an adaptation of the practices and content of engineering education curricula, towards more active learning approaches (Kolb and Kolb, 2005; Bassetto et al., 2011; Visich et al., 2012; Peillon et al., 2016; Medini, 2018).

This paper reports on a case study based lecture about MC, which has been given to students pursuing a Master of Science in Industrial Engineering. The lecture echoes the Kolb model for Experiential Learning and refers to guidelines about accreditation requirements. An analysis of the achievement of learning outcomes is performed based a students' survey conducted upon two different classes. 
The remainder of the paper is organised as follows: Section 2 provides a brief overview of the related background literature. Section 3 reports on a method for designing a course integrating an active learning approach and accreditation requirements. Section 4 shows a designed course following the proposed method. Section 5 discusses the achievement of the learning outcomes based on students' perceptions, considering two courses with different integration levels of experiential learning. Concluding remarks are given in Section 6.

\section{Background literature - experiential learning theory and application in engineering education}

Experiential Learning theory sees the learning as "the process whereby knowledge is created through the transformation of experience. Knowledge results from the combination of grasping and transforming experience". According the experiential learning theory, learning is a recursive process assimilated to a four-stage cycle spanning over: concrete experience (CE), reflective observation (RO), abstract conceptualization (AC), and active experimentation (AE) (Figure 1). Students can start learning through concrete experience that they observe and reflect upon, deriving from their reflection abstract concepts. They then draw new implications from these abstract concepts and test them through active experimentation (Kolb, 1984; Kolb and Kolb, 2005).

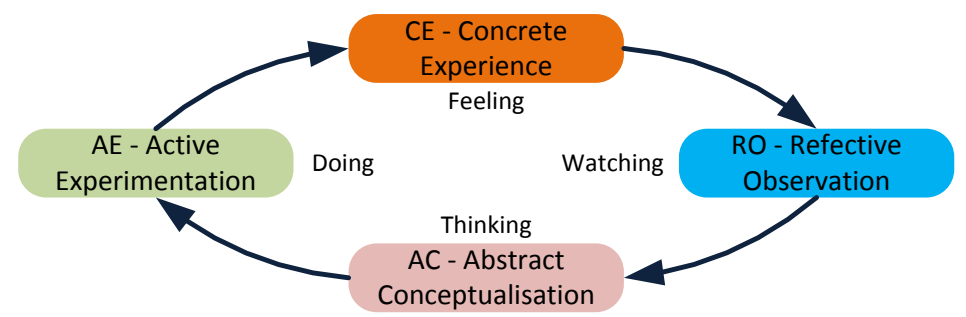

Fig. 1: Kolb learning cycle

Kolb and Kolb (2005) identified a number of educational principles that ensure the consistency of the experiential learning experience of the students and avoid misseducative experiences: respect for learners and their experience, begin learning with the learner's experience of the subject matter, creating and holding a hospital space for learning, making space for conversational learning, making space for development of expertise, making space for acting and reflecting, making spaces for feeling and thinking, making space for inside-out learning, making space for learners to take charges of their own learning. These practices within engineering courses support an improvement of the students' retention rate (Kolb and Kolb, 2005).

Experiential learning has been widely used in a variety of engineering education contexts and within many universities all over the world; examples of these are reported in the following research works (Bassetto et al., 2011; Visich et al., 2012; Medini, 2018). Despite the large use of experiential learning and the increasing awareness of its benefits to the students, guidelines for designing effective 
experiential learning courses or activities are scarce. Most of experiential learning applications are inspired by the basic learning cycle and design methods of the activities or courses, are either implicit or briefly presented.

\section{Course design following EUR-ACE guidelines and experiential learning principle}

This section provides a structured method for course design following an experiential learning principle. The method builds on EURA-ACE (European Accreditation for Engineering) guidelines for educational programmes design, and on learning cycle and educational principles from the experiential learning theory. More specifically, the general steps of the method are inspired by previous works on how to develop a programme based on accreditation criteria (EURA-ACE) (Chuchalin and Kriushova, 2011). The identification and articulation of learning modules and modes is inspired by the experiential learning cycle and educational principles.

Figure 2 shows the steps of the method, reported on in the boxes. Vertical arrows refer to the main used concepts from literature. Full line horizontal arrows illustrate the sequence of the steps, while the dashed arrows show some of the main iterations which occur during the design process. The general design steps are needs analysis, general objectives identification, learning outcomes definition, learning modules identification, building syllabus, and course assessment plan.

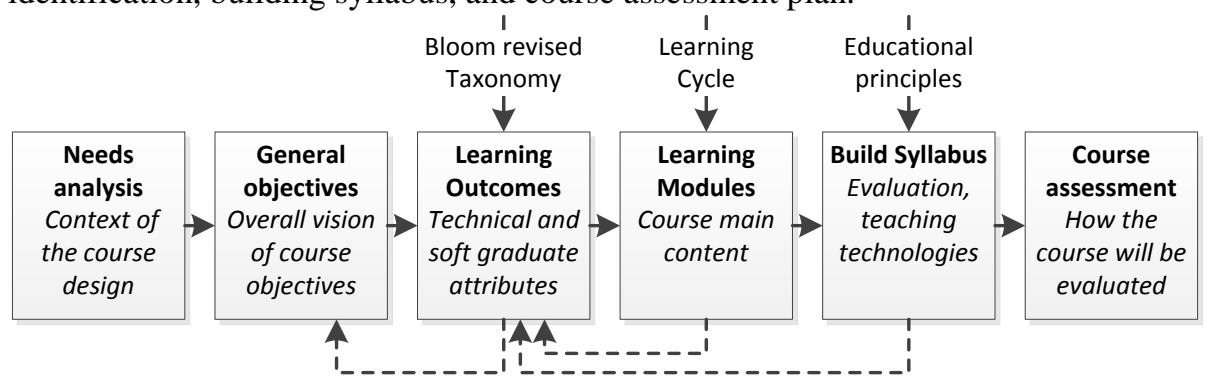

Fig. 2: Course design method

Needs analysis is recognized as an important step in course design which contributes towards more contextualised content (Lekatompessy, 2010). This step is expected to enlighten the course designers on the learners' current skills, knowledge gaps, objective and subjective needs, and on the expected use of the know-how and knowledge transmitted through the course. Needs analysis is not a one-shot action; on the contrary, it should support a continuous improvement process of the course.

Needs analysis contributes to the subsequent steps namely the formalisation of the course general objectives and learning outcomes. Similarly to the programme design context (ENAEE, 2005), in course design, the general objectives should reflect how the needs of the students (or any other targeted public) are met through the course.

Learning outcomes refer to the graduate attributes in terms of technical and soft skills that can be achieved through the course (Chuchalin and Kriushova, 2011). The definition of learning outcomes uses the revised taxonomy of Bloom (Krathwohl, 
2002). The dimensions of the revised taxonomy are as follows: Remember Retrieving relevant knowledge from long-term memory. Understand - Determining the meaning of instructional messages, including oral, written, and graphic. Apply Carrying out or using a procedure in a given situation. Analyze - Breaking material into its constituent parts and detecting how the parts relate to one another and to an overall structure or purpose. Evaluate - Making judgments based on criteria and standards. Create - Putting elements together to form a novel, coherent whole or make an original product.

In the next step of course design, the learning modules are identified and mapped to learning outcomes. The share of the grades among learning modules is partly based on learning modules importance to learning outcomes achievement. The identification of learning modules is inspired by experiential learning theory in order to define the learning cycle. The four learning stages of experiential learning theory are used as guidelines to identify the focus of each learning module. Altogether, learning modules should support a specific learning cycle.

The subsequent step, build syllabus, consists in defining how learning modules will be actually conducted (e.g. sequence, organisation, teaching technologies, etc.) and how the grades are assigned. This step is referred to in Figure 2 by Build Syllabus.

In the final step in course design, course assessment, the methods and ways of assessing the course will be designed. Usually, students' surveys are an easy-toimplement method and provide valuable insights into student perceptions.

\section{Designed MC course}

This section reports on the design of new course following the presented method, starting from a similar course which has been given to MSc students in 2016. The use of the method supported substantial modifications in both objectives and content of the course. Next paragraphs illustrate the six design steps.

Needs analysis. The course is developed within an MSc programme in Industrial Engineering. The students have backgrounds in industrial or mechanical engineering. They hold either a bachelor or an Engineer or equivalent MSc degree in these domains. Most of the students are international and come from Europe, North Africa, Asia and Latin America. This also means that the course language should be no other than English, as it is the most likely common language for all students. Within the context of industrial transition, the students lack a deep understanding of how business strategies such as MC could foster the industrial renewal and how they can actually be implemented.

General objectives. The objective of the course is threefold; first introduce MC as a customer centred strategy, second enlighten the students on how MC can actually be implemented in the manufacturing and service industries, third enhance students' research abilities and critical thinking.

Learning outcomes (LOs). The learning outcomes of the course are as follows:

- LO1 - Understand MC philosophy and main capabilities (choice navigation, solution space development, robust process design (Salvador et al. (2009)); 
- LO2 - Analyse how these capabilities can be put in practice;

- LO3 - Evaluate the experience of a given company with MC implementation;

- LO4 - Plan the required actions for a service company to benefit from MC;

- LO5 - Criticize the soundness of case studies analysis performed by other peers.

Learning modules (LMs). Learning modules include the following:

- LM1 - An introduction into the topic.

- LM2 - A seminal paper reading about MC capabilities.

- LM3 - Analysis of mass customisation case studies.

- LM4 - Review of peers' work about case studies analysis.

The planned contribution of learning modules to the learning cycle is reported on in Figure 3.

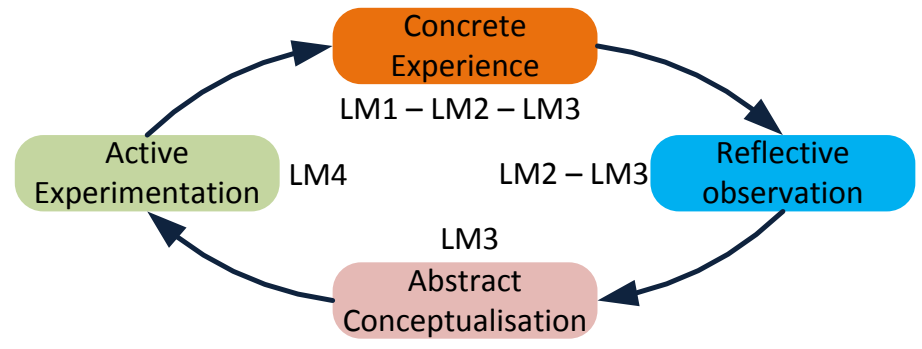

Fig. 3: LMs mapping to learning cycle

Table 1 reports on the mapping between learning modules and learning outcomes: a ' + ' in the crossing between a given row $i$ and a given column $j$ means that LM $i$ contributes to the achievement of LOj. Clearly, case studies (LM3) have the most significant contribution to learning outcomes. However, these cannot be achieved without the other learning modules altogether. This is quite expected because of the involvement of LM3 in various learning stages of the experiential learning cycle.

Table 1. LOs and LMs mapping

\begin{tabular}{cccccc}
\hline & LO1 & LO2 & LO3 & LO4 & LO5 \\
\hline LM1 & + & & & & \\
LM2 & + & + & & & \\
LM3 & + & + & + & + & \\
LM5 & & + & + & & + \\
\hline
\end{tabular}

Build syllabus. The course is organised as follows; LM1 is planned in the beginning so as to provide an introduction and the instructions to the students. Afterwards, students are left with the paper reading (LM2). A summary of the paper is required which enhances also the reflective observation activity in reference to experiential learning cycle. Upon finishing off with the seminal paper, students start working on three assigned case companies (LM3). The students are asked to report on how these companies implemented the three MC capabilities, seen in LM2. The provided input material consists basically of i) written interviews of mass customisation experts speaking about case companies' experiences with $\mathrm{MC}$, and ii) case companies' websites. A first deliverable including the article summary and case 
studies analysis is due one week after the beginning of the course. Then students are asked to identify the actions required to pursue $\mathrm{MC}$ considering an integrated product and service offering. A second deliverable summing up this effort is due two weeks after the beginning of the course. Upon receiving students' deliverables, a peer review process is launched and need to be finished within one week. A presentation session is planned few days later to discuss the case studies. The interactions between students are enhanced by their recent peer review experience.

Requisite skills can be met with an industrial engineering or engineering management background. The evaluation is based on the deliverable quality, the presentation and discussion, and a final exam about MC case.

Course assessment. The questionnaire will be given to students few days after the last session. A hard copy is used to increase the response rate and avoid nonexploitable answers. The questionnaire include the following sections: students background, MC implications to firms strategy and competitiveness, MC implications to variety management, MC implications to production and supply chain management, Experiential learning approach, and MC topic relevance. A full version of the questionnaire can be found in Medini (2018).

\section{Students perception and insights into learning outcomes achievement}

A survey was conducted in 2018 upon achieving the course. In order to evaluate the course improvement actions, the results were compared with the ones from a previous survey conducted in 2016 with another class taking the same course but with a different structure (Medini, 2018). Figure 4 depicts the aggregate results of the surveys according to the questionnaire sections.

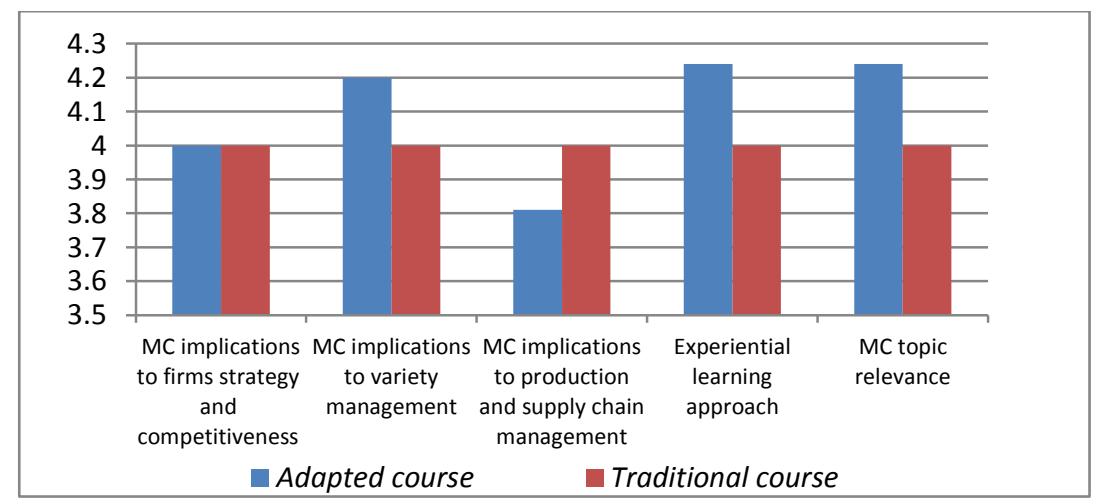

Fig. 4: Summary of the survey results

In the case of the adapted course, the sample size ranges between 12 and 13 while in the case of the traditional course the sample size is in the range $14-17$. The questions are answered using a 5 levels grid (1 strongly disagree, 5 strongly agree). In student surveys of the previous traditional course and the redesigned, adapted course, most of the students are international and have similar past education. 
Overall, it can be seen that there is an improvement in the achievement of the objectives. Unsurprisingly, MC implications to production and supply chain management were better grasped in the traditional course. This is because the case studies are not directed towards these topics. Moreover, the traditional course included two simulation sessions addressing partly production management issues. However, the perceptions of the students from the adapted course indicated that this course brings more evidence of the relevance of the MC topic, and of the experiential learning approach.

Figure 5 shows a world cloud derived from students' answers to the open-ended questions of the survey, related to the adapted course. The size of the words is proportional to their frequency of occurrence. The world cloud is generated by the $\mathrm{R}$ software (Ihaka and Gentleman, 1996) with the following rules: number of the words in the cloud should not exceed 30 (for the sake of readability), and minimum occurrence frequency of the words in students comments is 2 (to cover as many topics as possible).

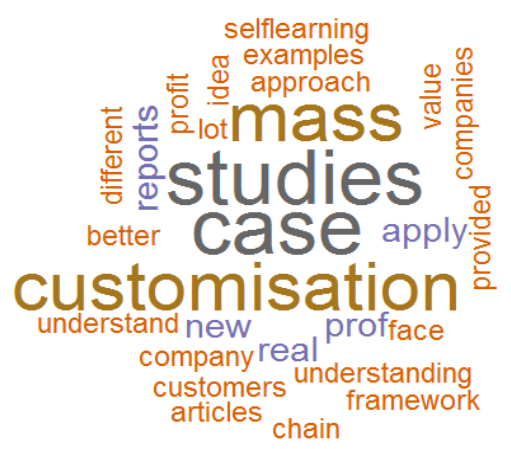

Fig. 5: Word cloud of students' comments

It can be seen that case studies are prevailing in the answers of the students, highlighting particularly a positive perception of the students. The case studies helped some students to understand '...in a more concrete and independent way how mass customisation is implemented...". Some other less frequent key words reflect the positive impact of the learning practices, e.g. self-learning, apply, real. Interestingly, the word "prof" (professor) appeared several times highlighting the need of some students to get continuous feedback on their work by the instructor. This can be addressed by intermediate discussion sessions. The survey revealed another potential improvement avenue that is, to visit companies and gain more insights into their experience with the mass customisation.

Although these findings need more evidence, they provide valuable insights into the impact of the proposed approach and into some potential improvement avenues.

\section{Conclusion}

The interdisciplinary topics brought by the industrial transition require proactivity on the side of academicians so as to design adapted course content and use appropriate 
teaching methods. This paper calls for integrating experiential learning theory and accreditation guidelines in the (re)design of courses in the engineering education domain to keep up with the industrial transition context. It was shown through the surveys that these approaches are likely to improve the achievement of the course objectives and student satisfaction.

\section{Acknowledgements}

The author would like to thank Omar Ezzat for his support in the peer review process and the management of the various deliverables from the students.

\section{References}

1. Bassetto, S., Fiegenwald, V., Cholez, C., and Mangione, F.: Experiencing Production Ramp-Up Education for Engineers. European Journal of Engineering Education 36 (4), 313-326 (2011).

2. Chuchalin, A., and Kriushova, A.: Engineering curriculum design based on accreditation criteria. In: SEFI Annual Conference, pp. 641-644. European Society for Engineering Education, Lisbon (2011).

3. ENAEE - European Network for Accreditation of Engineering Education: EUR-ACE, http://www.enaee.eu/wp-assets-enaee/uploads/2015/04/EUR-ACE-Framework-Standardsand-Guidelines-Mar-2015.pdf, last accessed April 2018 (2005).

4. Ihaka, R., Gentleman, R.: R: A language for data analysis and graphics. Journal of Computational and Graphical Statistics 5, 299 - 314 (1996).

5. Kolb, A. Y., and Kolb, D.A.: Learning Styles and Learning Spaces: Enhancing Experiential Learning in Higher Education. Academy of Management Learning \& Education 4 (2), 193-212 (2005).

6. Kolb, D.A.: Experiential learning: experience as the source of learning and development, Prentice Hall, New Jersey (1984).

7. Krathwohl, D.R.: A Revision of Bloom's Taxonomy: An Overview. Theory Into Practice 41(4), 212-218 (2002).

8. Lekatompessy, F.M.: Needs Analysis in Curriculum Development Report on the Third Chapter of Jack Richard's book (Curriculum Development in Language Teaching), Cambridge University Press, Cambridge (2002).

9. Medini, K.: Customer order fulfilment in mass customization context: an agent based approach. International Journal of Simulation and Process Modelling 10(4), 334-349 (2015).

10. Medini, K.: Teaching customer-centric operations management - evidence from an experiential learning-oriented mass customisation class, European Journal of Engineering Education 43(1), 65-78 (2018).

11. Peillon, S., Medini, K., Dubruc, N.: An initial training program on Product-Service Systems and servitization for engineering students. Procedia CIRP, 282-287, (2016).

12. Salvador, F., Holan, P.M. \& Piller F.: Cracking the Code of Mass Customization. MIT Sloan Management 50(3), 70 - 78 (2009).

13. Visich, J. K., Gu, Q., and Khumawala. B.M.: B2C Mass Customization in the Classroom. Decision Sciences Journal of Innovative Education 10 (4), 521-545 (2012). 